\title{
House dust mite sensitivity in childhood asthma
}

\author{
J. O. WARNER AND J. F. PRICE
}

From the Respiratory Unit, The Hospital for Sick Children, Great Ormond Street, London

SUMMARY The clinical features of perennial asthmatic children with a skin or bronchial reaction to the house dust mite (Dermatophagoides pteronyssinus) were compared with those of asthmati children without mite sensitivity. Mite sensitive asthma was characterised by an early age of onse黑 of symptoms, these being predominantly nocturnal. A history of wheezing precipitated by dusक exposure, during vacuuming, bedmaking, or dusting was present in $52 \%$ of cases. Asthmati\& children with mite sensitivity were more likely to have been born at the time of the year when miteo counts were highest. This was consistent with the idea that allergy may be associated with a period of susceptibility to sensitisation in early infancy.

Asthma precipitated by exposure to dust has been recognised for three centuries (Van Helmont, 1662), but the link between house dust and house mite allergy in asthmatic patients was not described until 1964 (Voorhorst et al.). Skin tests (MorrowBrown and Filer, 1968), bronchial provocation tests (Aas, 1970), in vitro tests measuring IgE antibodies (Stenius and Wide, 1969), and histamine release from leucocytes (McAllen et al., 1970) have clearly indicated that the mite, Dermatophagoides pteronyssinus, is one of the commonest allergens in Europe to which asthmatic patients are sensitised.

Sensitivity to $D$. pteronyssinus is common in childhood asthma (Sarsfield, 1974) but little has been published on the characteristics of such an allergy. The clinical importance of any one allergy in an asthmatic child with multiple allergen sensitivities can ultimately only be determined by history. There is an impression of an association between nocturnal asthma occurring throughout the year and house mite sensitivity, but this has not been established. Therefore, we have compared aspects of the clinical history of asthmatic children with and without a skin or bronchial reaction to D. pteronyssinus.

\section{Patients and methods}

Eighty-five children (62 boys and 23 girls) with moderate to severe perennial asthma, aged between 5 (the minimum for performing bronchial provocation tests adequately) and 14 years were studied.

Received 9 February 1978
Bronchial asthma was diagnosed by clinical an laboratory evidence of intermittent airways ob struction, reversible to a degree by bronchodilators All the children had at least 6 moderately sever\& attacks of wheezing each year and their asthma was not satisfactorily controlled on bronchodilaters alone.

The children were admitted to hospital forJas least $\mathbf{4 8}$ hours. A full clinical history and examinatio was recorded on a standard questionnaire. Each ha\& prick skin tests on the forearms to 10 allergens an $\Phi$ a control solution. The reactions were measure after 20 minutes using a gauge, and weals of $2 \mathrm{mr}$ diameter or greater were recorded as positive. The children had a bronchial provocation test to solube extracts of $D$. pteronyssinus, using the method described by Warner (1976).

The medical notes of a further 163 unselecte asthmatic children were studied to abstract in formation on skin test responses, date of birth, agie of onset of wheezing, and the presence of nocturna attacks.

Statistical analyses used the $\chi^{2}$ test with con? tinuity correction.

\section{Results}

Sixty-nine $(81 \%)$ of the 85 children had a positive bronchial provocation test (BPT) to D.pteronyssinus and were designated as mite sensitive. 16 had no bronchial response to this allergen and, of these, 9 on whom further tests were made had positis bronchial reactions to other allergens (4 Timothy grass, 3 cat fur, 1 Alternaria tenuis, and 1 Cladgs sporium herbarum). 
Skin test responses to 10 allergens in each group of patients are shown in Table 1. Only one patient had totally negative skin tests, but she had marked bronchial lability and a family history of allergic disease. All 8 patients with negative skin tests to D. pteronyssinus also had negative BPTs to this allergen, but $8(11 \%)$ of the positive skin reactors had negative BPTs. Significantly more of the mite sensitive group reacted to house dust extract and feathers. Fewer mite sensitive children reacted to the moulds Cladosporium and Aspergillus fumigatus, but this was significant only for the latter allergen.

Equal numbers of patients in each group had at least one first-degree relative with asthma, eczema, or hay fever. Both eczema and perennial rhinitis were more common in the mite sensitive group but this did not reach significance. $36(52 \%)$ of 69 mite sensitive children had a clear history of asthma precipitated by exposure to dust during dusting, vacuuming, or bed-making compared with $3(19 \%)$ of 16 in the mite negative group (Table 2).

Some studies were done retrospectively and of 163 asthmatic children, $120(74 \%)$ had positive skin tests to $D$. pteronyssinus. The mite positive children gave a history of frequent nocturnal wheezing significantly more often (102 of 120) than did the mite negative group (18 of $43 ; \chi^{2} 28 \cdot 15, P<0.0005$ ).

As there were too few mite negative patients from the BPT for some analyses, they were grouped with 40 children who had negative skin tests to the mite from the retrospective study. The appropriate information was not available for the remaining 3 patients with negative skin tests to the mite from that study. It is reasonable to assume that children with negative skin tests to the mite would also have a negative BPT to this allergen, as the association between negative skin tests and BPTs is at least 95\% (Spector and Farr, 1974; Bryant et al., 1975).

Significantly more of the mite sensitive children were born between July and December than at other times, and more mite sensitive patients had developed asthma before the age of 2 than the mite nonsensitive patients (Table 3). The Figure shows the

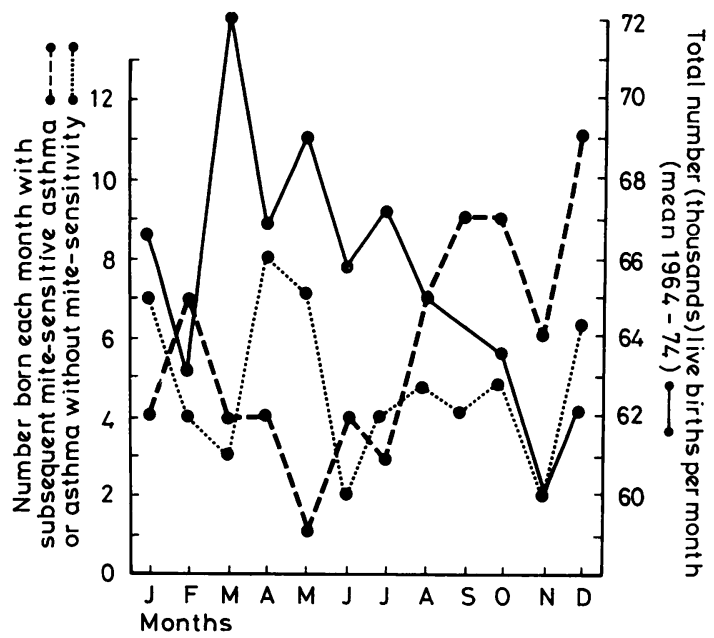

Figure Month of birth of children with mite-sensitive asthma or asthma without mite sensitivity compared with the Registrar General's mean figures for total live births each month for 1964 to 1974.

Table 1 Number of positive prick skin test reactions to 10 allergens in asthmatic children with and without a bronchial sensitivity to the house dust mite (Dermatophagoides pteronyssinus); the $\chi^{2}$ and $P$ values for the associations of the reactions to each skin test with bronchial challenge response to mite are given

\begin{tabular}{|c|c|c|c|c|c|c|c|c|c|c|}
\hline \multirow[b]{2}{*}{$\begin{array}{l}\text { Bronchial } \\
\text { challenge } \\
\text { to mite }\end{array}$} & \multicolumn{10}{|c|}{ No. of positive prick skin tests } \\
\hline & D.pteronyssinus & $\begin{array}{l}\text { House } \\
\text { dust } \\
\text { extract }\end{array}$ & Feathers & Cat & Milk & $\begin{array}{l}\text { Timothy } \\
\text { grass }\end{array}$ & Cocksfoot & A.tenuis & C.herbarum & A. fumigatus \\
\hline $\begin{array}{l}\text { Positive (69) } \\
\text { Negative (16) } \\
\chi^{2} \\
\mathbf{P}\end{array}$ & $\begin{array}{r}69 \\
8 \\
-\end{array}$ & $\begin{array}{l}64 \\
10 \\
8 \cdot 04 \\
<0.005\end{array}$ & $\begin{array}{l}52 \\
6 \\
6.93 \\
<0.01\end{array}$ & $\begin{array}{l}49 \\
10 \\
0 \cdot 13 \\
\text { NS }\end{array}$ & $\begin{array}{l}14 \\
5 \\
0 \cdot 38 \\
\text { NS }\end{array}$ & $\begin{array}{l}42 \\
12 \\
0 \cdot 59 \\
\text { NS }\end{array}$ & $\begin{array}{l}40 \\
11 \\
0 \cdot 26 \\
\text { NS }\end{array}$ & $\begin{array}{l}17 \\
6 \\
0 \cdot 53 \\
\text { NS }\end{array}$ & $\begin{array}{l}19 \\
8 \\
2 \cdot 08 \\
\text { NS }\end{array}$ & $\begin{array}{l}11 \\
8 \\
6 \cdot 83 \\
<0 \cdot 01\end{array}$ \\
\hline
\end{tabular}

NS $=$ Not significant $P>0.05$.

Table 2 Aspects of the clinical histories in children with and without a bronchial reaction to the house dust mite

\begin{tabular}{|c|c|c|c|c|c|c|c|c|}
\hline & \multicolumn{2}{|c|}{$\begin{array}{l}\text { First-degree family } \\
\text { history of atopy* }\end{array}$} & \multicolumn{2}{|c|}{ Eczema } & \multicolumn{2}{|c|}{ Perennial rhinitis } & \multicolumn{2}{|c|}{$\begin{array}{l}\text { History of } \\
\text { dust exposure }\end{array}$} \\
\hline & + & - & + & - & + & - & + & - \\
\hline $\begin{array}{l}\text { Mite sensitive } \\
\text { Mite insensitive }\end{array}$ & $\begin{array}{r}38 \\
9\end{array}$ & $\begin{array}{r}31 \\
5\end{array}$ & $\begin{array}{r}40 \\
7\end{array}$ & $\begin{array}{r}29 \\
9\end{array}$ & $\begin{array}{r}40 \\
6\end{array}$ & $\begin{array}{l}29 \\
10\end{array}$ & $\begin{array}{r}36 \\
3\end{array}$ & $\begin{array}{l}33 \\
13\end{array}$ \\
\hline $\begin{array}{l}\chi^{2} \\
P\end{array}$ & \multicolumn{2}{|c|}{$\begin{array}{l}0.11 \\
\text { NS }\end{array}$} & \multicolumn{2}{|c|}{$\begin{array}{l}0.57 \\
\text { NS }\end{array}$} & \multicolumn{2}{|c|}{$\begin{array}{l}1.45 \\
\text { NS }\end{array}$} & \multicolumn{2}{|c|}{$\begin{array}{l}4.58 \\
<0.05\end{array}$} \\
\hline
\end{tabular}

* 2 mite insensitive patients adopted, so family history not available. 
Table 3 Age at onset of symptoms and month of birth of asthmatic children with a bronchial reaction to the house dust mite compared with asthmatic children with negative skin or bronchial provocation tests to the mite

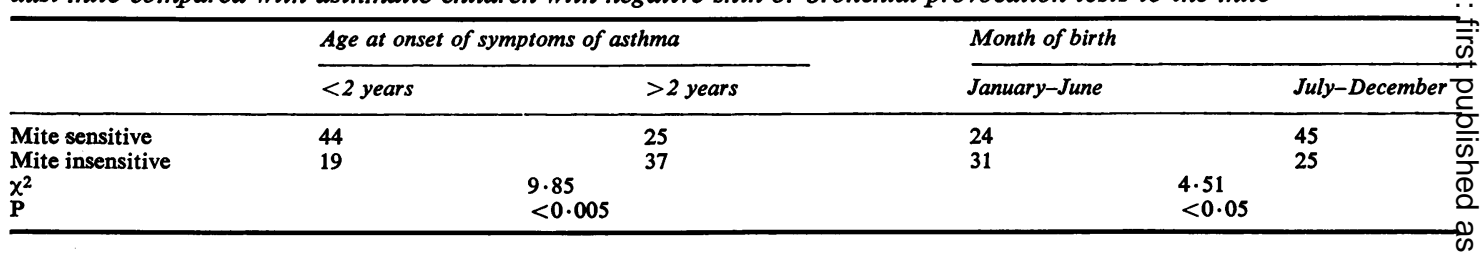

months of birth compared with the Registrar General's figures for total live births with peaks in April to May, and December to January. The mite sensitive children were born in greater numbers from August to December, when there were fewer live births.

\section{Discussion}

The children for the BPT study were carefully selected as having severe perennial asthma. The male to female ratio of $2 \cdot 7: 1$ was similar to that found by McNicol and Williams (1973) in their severe asthmatics. Over half had at least one first-degree relative with an atopic disease, usually a parent. Few accurate figures of the incidence of allergy in families of asthmatic patients are available. Smith (1974) found that $87 \%$ of allergy clinic children had positive family histories, but he did not distinguish first-degree relatives from others.

Sarsfield (1974) found a $23 \%$ incidence of wheezing precipitated by dust exposure in 133 unselected asthmatic children and concluded that history was of limited use, but the analysis did not separate mite sensitive and insensitive children. We found that a positive history of wheezing on dust exposure strongly suggested mite sensitivity, and this indicates that such a history is useful for identifying perennial asthmatics with mite sensitivity.

Nocturnal wheezing was significantly more common in the children with skin hypersensitivity to the mite than in those without this allergy. $D$. pteronyssinus is found most often in mattress dust and bedding, so nocturnal symptoms may be expected to predominate in asthmatics sensitive to this allergen. It confirms the uncontrolled observation of Morrison Smith (1970) that $82 \%$ of asthmatic children with skin test mite sensitivity often had nocturnal attacks and had little seasonal variation in frequency of symptoms.

15 The high incidence of asthma deaths in the early morning (Cochrane and Clark, 1975) has prompted a reinvestigation of nocturnal and early morning wheezers (Hetzel et al., 1977). The explanation is not clear, but there may be a circadian variation in airway calibre which makes wheezing more likely to occur after allergen provocation during the night (Gervais et al., 1977). Our data suggest that mite $\vec{\omega}$ sensitivity may be an important factor in nocturna asthma at least in childhood.

A high proportion of children with positiver results to the BPT had other manifestations of allergic disease, $55 \%$ with eczema, $54 \%$ perenniak rhinitis, $12 \%$ hay fever, and $16 \%$ urticaria. Nasa $\bar{b}$ symptoms are common in childhood asthma (Vinero and Jackman, 1976), and the histories suggested that these symptoms contributed significantly to oures patients' overall disability. The slightly increasedo prevalence of perennial rhinitis in the mite sensitive $\frac{\mathbb{D}}{3}$ children suggests that this may be another manifestation of mite allergy, although this would require confirmation by nasal challenge tests.

There is no large series of mite BPTs in asthma更co children but Aas (1970) reported that $53 \%$ of selected asthmatic children had positive reactions after BPTs to house dust extract. House dust and mite extracts are not strictly comparable, but the correlation of positive reactions to the two allergens is $\frac{Q}{\square}$ good (Voorhorst et al., 1969). It is possible that our $\overrightarrow{\vec{F}}$ higher incidence of positive BPT reactions to mite윽 may result from the fact that our patients had more $-{ }_{-}$ severe perennial asthma. An early age of onset of wheezing in the study by McNicol and Williams (1973) was associated with more severe disease and응 our mite sensitive children more often developed:symptoms before 2 years of age than the mite 3 . nonsensitive children. This provides further indirect $\delta$ evidence that mite sensitive asthma is severe.

The children who had BPTs to D. pteronyssinuso reacted to a variety of allergens on skin testing. As mite is the principal component of house dusto extract (Voorhorst et al., 1964), it is not surprising that more mite sensitive children reacted to houseo dust extract. It is interesting that more also reacted N to feathers. Wormald (1971) suggested that reactions N to feathers were caused by mite-allergens in the $\sigma$ extract, possibly poultry mites with cross-antigenicity with the house dust mite. Fewer mite sensitive children reacted to $A$. fumigatus. As the $\stackrel{\infty}{\rightarrow}$ patients were selected with perennial asthma perhaps the perennial cause in the mite insensitive patients $\vec{O}^{\circ}$ was the mould allergy. 
The different distribution of month of birth between the 2 groups of asthmatics was striking. A comparison with total live births each month showed that the different distribution of month of birth of the mite sensitive children was a genuine one, and not due to general trends in month of birth. Other studies have demonstrated some inconclusive differences of birth season in patients with mite sensitivity in a small prospective study (Soothill et al., 1976); seasonal or perennial symptoms (Pearson et al., 1977); and skin test reactions to mixed allergen preparations (Bjorkstén and Suoniemi, 1976). This study is the first to show clear differences in month of birth in asthmatic children with an accurately identified allergy to $D$. pteronyssinus.

The largest number (26) of mite sensitive asthmatics were born in the quarter October to December and the smallest (9) in April to June. These quarters correspond respectively to the finding of the highest and lowest frequencies of live mites in house dust (Blythe, 1976). The development of allergy may be associated with a period of susceptibility to sensitisation in early infancy. This was suggested by Taylor et al. (1973) who demonstrated an association between the delayed development of serum IgA in infants who subsequently had eczema and positive results to skin tests. This idea is supported by the data presented, with mite sensitive asthmatic children being born at times when they would have a high mite exposure during their early months of maximum susceptibility to sensitisation.

We thank The Hospital for Sick Children Research Board for J.O.W.'s grant and the Medical Research Council for J.F.P.'s training fellowship; Dr E. N. Hey, Dr A. P. Norman, and Professor J. F. Soothill for allowing study of their patients and for stimulation and encouragement; and to Mrs G. Giles for secretarial assistance.

\section{References}

Aas, K. (1970). Bronchial provocation tests in asthma. Archives of Disease in Childhood, 45, 221-228.

Björkstén, F., and Suoniemi, I. (1976). Dependence of immediate hypersensitivity on the month of birth. Clinical Allergy, 6, 165-171.

Blythe, M. E. (1976). Some aspects of the ecological study of the house dust mites. British Journal of Diseases of the Chest, 70, 3-31.

Bryant, D. H., Burns, M. W., and Lazarus, L. (1975). The correlation between skin tests, bronchial provocation tests, and the serum level of IgE specific for common allergens in patients with asthma. Clinical Allergy, 5, 145-157.

Cochrane, G. M., and Clark, T. J. H. (1975). A survey of asthma mortality in patients between ages 35 and 64 in the Greater London hospitals in 1971. Thorax, 30, 300-305.
Gervais, P., Reinberg, A., Gervais, C., Smolensky, M., and De France, O. (1977). Twenty-four hour rhythm in the bronchial hyperreactivity to house dust in asthmatics. Journal of Allergy and Clinical Immunology, 59, 207-213.

Hetzel, M. R., Clark, T. J. H., and Houston, K. (1977). Physiological patterns in early morning asthma. Thorax, 32, 418-423.

McAllen, M. K., Assem, E. S. K., and Maunsell, K. (1970). House dust mite asthma. Results of challenge tests on five criteria with Dermatophagoides pteronyssinus. British Medical Journal, 2, 501-504.

McNicol, K. N., and Williams, H. B. (1973). Spectrum of asthma in children. I. Clinical and physiological components. British Medical Journal, 4, 7-11.

Morrison Smith, J. (1970). Clinical findings in children with allergy to house dust mites. Acta allergologica, 25, 37-40.

Morrow Brown, H., and Filer, J. L. (1968). Role of mites in allergy to house dust. British Medical Journal, 3, 646-647.

Pearson, D. J., Freed, D. L. J., and Taylor, G. (1977). Respiratory allergy and month of birth. Clinical Allergy, 7, 29-33.

Sarsfield, J. K. (1974). Role of house dust mites in childhood asthma. Archives of Disease in Childhood, 49, 711-715.

Smith, J. M. (1974). Incidence of atopic disease. Medical Clinics of North America, 58, 3-24.

Soothill, J. F., Stokes, C. R., Turner, M. W., Norman, A. P., and Taylor, B. (1976). Predisposing factors in the development of reaginic allergy in infancy. Clinical Allergy, 6, 305-319.

Spector, S. L., and Farr, R. S. (1974). Bronchial inhalation procedures in asthmatics. Medical Clinics of North America, 58, 71-84.

Stenius, B., and Wide, L. (1969). Reagin antibody (IgE), skin and provocation tests to Dermatophagoides culinae and house dust in respiratory allergy. Lancet, 2, 455-458.

Taylor, B., Norman A. P., Orgel, H. A., Stokes, C. R., Turner, M. W., and Soothill, J. F. (1973). Transient IgA deficiency and pathogenesis of infantile atopy. Lancet, 2, 111-113.

Van Helmont, J. B. (1662). Physick Refined. Lodwick Lloyd: London.

Viner, A. S., and Jackman, N. (1976). Retrospective survey of 1271 patients diagnosed as perennial rhinitis. Clinical Allergy, 6, 251-259.

Voorhorst, R., Spieksma-Boezeman, M. I. A., and Spieksma, F. T. M. (1964). Is a mite (Dermatophagoides sp.) the producer of the house dust allergen? Allergie und Asthmaforschung, 10, 329-334.

Voorhorst, R., Spieksma, F. T. M., and Varekamp, H. (1969). House Dust Atopy and the House Dust Mite Dermatophagoides pteronyssinus (Trouessart, 1897). Stafleu: Leiden.

Warner, J. O. (1976). Significance of late reactions after bronchial challenge with house dust mite. Archives of Disease in Childhood, 51, 905-911.

Wormald, P. J. (1971). Cross reactions in skin tests between house dust mite extract and feather extract. Clinical Allergy, 1, 291-293.

Correspondence to Dr J. O. Warner, Respiratory Unit, The Hospital for Sick Children, Great Ormond Street, London WC1N 3JH. 